Hydrology and Earth System Sciences, 2(2-3), 239-255 (1998) C EGS

\title{
Modelling root water uptake in a complex land surface scheme coupled to a GCM
}

\author{
Patricia de Rosnay and Jan Polcher \\ Laboratoire de Météorologie Dynamique du CNRS, Paris, France
}

\begin{abstract}
The aim of this paper is to improve the representation of root water uptake in the land surface scheme SECHIBA coupled to the LMD General Circulation Model (GCM). Root water uptake mainly results from the interaction between soil moisture and root profiles. Firstly, one aspect of the soil hydrology in SECHIBA is changed: it is shown that increasing the soil water storage capacity leads to a reduction in the frequency of soil water drought, but enhances the mean evapotranspiration. Secondly, the representation of the soil-vegetation interaction is improved by allowing a different root profile for each type of vegetation. The interaction between sub-grid scale variabilities in soil moisture and vegetation is also studied. The approach consists of allocating a separate soil water column to each vegetation type, thereby 'tiling' the grid square. However, the possibility of choosing the degree of soil moisture spatial heterogeneity is retained. These enhancements of the land surface system are compared within a number of GCM experiments.
\end{abstract}

\section{Introduction}

It is widely recognized that land hydrology plays a fundamental role in the climate. In General Circulation Models (GCMs), the parameterization of land surface processes is important as it determines the lower boundary conditions of the model and the partitioning of energy between sensible and latent heat fluxes (Mintz, 1984; Shukla and Mintz, 1982; Manabe, 1969).

The partitioning of energy between sensible and latent heat fluxes is also linked to seasonal variability of soil moisture which influences the low frequency atmospheric variability (Delworth and Manabe, 1988). Milly and Dunne (1994) have estimated the sensitivity of the global water cycle to soil water storage capacity. Their study emphasizes the fact that the land surface energy balance is strongly influenced by the soil moisture storage capacity.

A realistic representation of the land surface energy balance in GCMs depends also on the representation of subgrid scale processes. One GCM grid cell typically encloses a region of $300 \mathrm{~km} \times 300 \mathrm{~km}$, in which there can be a wide range of vegetation and bare surface types. Some land surface schemes do take account of sub-grid scale variations in soil type, infiltration capacity, or in vegetation type differing structurally or physiologically (Bonan, 1995; Bonan et al., 1993; Ducoudré et al., 1993; Johnson et al., 1993; Koster and Suarez, 1992; Wood et al., 1992; Avissar and Pielke, 1989; Entekhabi and Eagleson, 1989). Each con- centrates on a few aspects of the problem of dealing with land surface heterogeneity. One method currently used to represent the spatial inhomogeneities is a statistical one in which a probability density function is used to describe the variability of a particular land surface characteristic within the grid-box (Bonan, 1995; Bonan et al., 1993; Wood et al., 1992; Entekhabi and Eagleson, 1989). Another method, used in SECHIBA, is the sub-division of the grid box into several land tiles (Ducoudré et al., 1993; Koster and Suarez, 1992; Avissar and Pielke, 1989).

In this study, a representation of the sub-grid scale variation of soil moisture is linked to that of vegetation type already present in the model. Their interactions will be studied. The spatial heterogeneity within the grid is represented by a mosaic of vegetation patches. To each vegetation tile a corresponding soil tile is added, but the possibility of homogeneous soil moisture within the grid is retained. This possibility of choosing between distinct or common soil moisture for all vegetation tiles within a gridbox allows the role of soil moisture stress to be studied in two very contrasting simulations: (i) homogeneous but well separated tiles of vegetation within a grid box (ii) a well mixed distribution of vegetation types within the grid. The sub-grid scale variability of vegetation is also improved by accounting for different vertical root distributions for each vegetation type. Desborough (1997) has shown that transpiration is strongly sensitive to vertical root distribution. 
The impact of the improved representation of water uptake by roots on the calculated transpiration of different vegetation types is studied.

The improved land surface scheme is validated directly in the LMD GCM. Although the analysis of the results is more complex because of biases present in the simulated climate, the approach is global, and allows the interactions of the surface scheme to be tested with a wide spectrum of climate types.

Following a description of SECHIBA, the deficiencies of the reference version of SECHIBA coupled to the LMD GCM are analyzed and discussed. This indicates that an increase in soil moisture storage capacity could solve some of the problems. An experiment with a larger soil moisture storage capacity is conducted and the results of this experiment are compared to those of Milly and Dunne (1994). Following a description of the modifications to SECHIBA to allow a representation of a root density profile for each vegetation type present in the grid, and sub-grid scale variability of soil moisture, results of the new version of the model are presented and discussed.

\section{Description of the land surface scheme SECHIBA}

SECHIBA is a parameterization of the hydrological exchanges between the soil vegetation system and the atmosphere. It was developed by Ducoudré et al. (1993) to use within a general circulation model. In the following description of the land surface scheme, the sources of the equations are shown in order to explain their potentials and limits. SECHIBA receives climatic forcing from the GCM and computes the exchange coefficients between the soil and the atmosphere for each grid-cell of the model. In each grid-cell, up to eight land surface types can be present simultaneously: bare-soil, tundra, grass steppe, savannah, conifers, deciduous forest, and tropical forest. Each of them occupies a specified fraction of the surface of the mesh. For each of these vegetation types, latent heat fluxes are computed independently. A mean flux for the grid-cell is then computed from a weighted average of these fluxes. All the tiles share the same atmospheric forcing and one type of soil.

\section{SOIL HYDROLOGY}

SECHIBA is based on the Choisnel hydrological model (Choisnel et al., 1995; Polcher, 1994; Choisnel, 1977). The soil column is considered to consist of two moisture layers: a superficial and a lower one. The total depth of the soil is a parameter, $h_{t}\left(h_{t}=1 \mathrm{~m}\right.$ in SECHIBA), and it has a maximum water content of $W_{\max }$ which is obtained by integrating the maximum soil water amount per unit of soil volume $\left(r u u_{\max }\right.$, chosen at $150 \mathrm{~kg} \mathrm{~m}^{-3}$ in this version of the scheme) over the entire depth $h_{t}$. The behaviour of the upper reservoir is more complex than that of a simple bucket as its depth is time dependent. The soil moisture of this reservoir $\left(W_{u}\right)$ is controlled by the moisture convergence:

$$
\frac{\partial W_{u}}{\partial t}=P-E-D
$$

For simplicity, $P$ in this case is precipitation reaching the ground but it could also include snow and ice melt. $E$ is soil water loss through evaporation or transpiration of plants. $D$ is the drainage between the two soil layers. A saturated soil moisture ( $W_{\text {umax }}$ ) can also be defined by integrating $r u u_{\max }$ over the depth of the upper reservoir $\left(h_{u u}\right)$.

For variations in the depth of the upper reservoir, two cases have to be distinguished.

(i) The first one occurs when soil moisture in the upper reservoir is lower than its saturated value. In this case the depth can be reduced only by drainage:

$$
\frac{\partial h_{u u}}{\partial t}=\frac{-D}{r u u_{\max }}
$$

(ii) If the upper reservoir is saturated, soil moisture is maintained at its saturated value. The depth of the upper reservoir increases in situations of moisture convergence:

$$
\frac{\partial h_{u u}}{\partial t}=\frac{P-E-D}{r u u_{\max }} \text { if } P-E>0
$$

The upper reservoir exists as long as $W_{u}$ is larger than zero and $W_{u}+W_{d}<W_{\max }$ (where $W_{d}$ is the soil moisture in the deep reservoir). The upper reservoir is created as soon as precipitation is larger than evaporation.

When there is no upper reservoir, the deep reservoir works as a simple bucket. Its soil moisture varies with time according to the following equations:

$$
\begin{gathered}
\frac{\partial W_{d}}{\partial t}=P-E ; R=0 \text { if } W_{d}<W_{\max } \text { or } P-E<0 \\
W_{d}=W_{\max } ; R=P-E \text { if } W_{d} \geq W_{\max } \text { and } P-E \geq 0
\end{gathered}
$$

where $R$ is the runoff. In the presence of an upper reservoir, drainage is the only process which can increase the water content of the deep reservoir.

\section{DRAINAGE}

SECHIBA computes drainage between two adjacent soil layers according to the formulation used in the ARNO scheme described by Ducharne et al. (1997), Dümenil and Todini (1992) and Rowntree and Lean (1994). Two regimes are allowed depending on water availability in the upper soil layer. Drainage $D$ from the superficial soil layer toward the deep layer is given by:

$$
D=D_{\min } \frac{W_{u}}{W_{u \max }} \text { if } W_{u}<W_{\lim }
$$




$$
\begin{aligned}
D= & D_{\min } \frac{W_{u}}{W_{u \max }}+\left(D_{\max }-D_{\min }\right)\left(\frac{W_{u}-W_{\lim }}{W_{u \max }-W_{\lim }}\right)^{b} \\
& \text { if } W_{u} \geq W_{\lim }
\end{aligned}
$$

$W_{\text {lim }}$ is $0.75 \times W_{\text {umax. }} . D_{\min }, D_{\max }$ and $b$ are adjustable parameters chosen to be $0.002 \mathrm{~mm} \mathrm{~h}^{-1}, 0.2 \mathrm{~mm} \mathrm{~h}^{-1}$ and 1.5 , respectively. The drainage is larger when the soil moisture of the superficial layer is greater than $W_{l i m}$.

\section{CONTROL OF EVAPORATION BY THE SOIL-PLANT SYSTEM}

In SECHIBA, soil moisture controls evaporation through two variables: a water uptake function $\left(U_{s}\right)$ and soil resistance $\left(r_{\text {sail }}\right)$. The first variable is used for transpiration and combines root properties and soil moisture. The second variable controls bare soil evaporation.

In order to define these two variables, an assumption has to be made concerning the vertical distribution of moisture in each layer. A step function was chosen to define the moisture profile. In the general case where the soil contains several layers, a dry soil height $h_{l d}$ below which soil is at saturation and above which soil is dry is introduced for each layer $l$. The dry soil height can easily be determined by:

$$
W_{l}=\int_{0}^{h_{l \mid}} \operatorname{ruu}(z) E\left(z-h_{l d}\right) d z ; l \in u, d
$$

where $z$ is the vertical coordinate, distance from the surface, positive downward, $W_{l}$ is soil moisture in layer $l$, $\operatorname{ruu}(z)$ is the equivalent water depth per unit of length at level $z, h_{l u}$ is the thickness of the layer $l$ and $E(z)$ is the Heaviside step function. Observed root density distributions within soil are very close to an exponential function (Le Roux, 1995; Nepstad et al., 1994; Akpo, 1992; Grouzis, 1988; Kalisz et al., 1987; Gale and Grigal, 1987). Thus the root density profile, $R(z)$, can be characterized by a single number $c$ :

$$
R(z)=e^{-c z}
$$

The ability of roots to extract water for a given relative soil moisture must be represented. Any function, $\beta_{\text {root }}$, which varies between 1 for saturated soil and 0 for dry soil could be used. In SECHIBA, a Heaviside distribution is chosen and only the two extreme values are used. That allows the equation defining the water uptake function to be written as the integral of the stress exercised by the roots normalized over the depth of the soil. Thus $U_{s}$ varies between 0 and 1 . The calculation of $U_{s}$ for layer $l$ is:

$$
U_{s}=\frac{\int_{0}^{\infty} \beta_{r o t}\left(E\left(z-h_{l d}\right) r u u_{\max }\right) R(z) d z}{\int_{0}^{\infty} \beta_{r o o t}\left(r u u_{\max }\right) R(z) d z}
$$

After integration this equation becomes:

$$
U_{s}=e^{-c h_{l d}}
$$

The integration is carried out from the surface through a bottomless soil column in order to include the entire root system of the plant and to obtain a function which is independent of the total soil depth. This formulation does not take into account that the reservoir has a limited depth and a finite volume of water. This is not a problem as long as the height of dry soil is smaller than the total soil depth. Because of the exponential structure of the root system, the water uptake function tends rapidly towards zero as the dry soil height increases. Thus, for large values of the total soil depth $h_{t}$ or $c$, the soil should never dry out. Unrealistic situations in which the soil becomes totally dry are thereby avoided. In contrast to other land surface schemes, rooting depths have to be prescribed. The parameter $c$ of root profiles is critical; it should depend largely on the vegetation type and can thus be determined, but in the original version of SECHIBA only one value of $c$ is used.

The above discussion applies to the upper and lower reservoirs. When both soil moisture reservoirs are present, the dry soil height of the upper and lower reservoirs can be weighted differently in the calculation of $U_{s}$. When it rains, the upper roots which are in the wetted part of the soil are more efficient in contributing water to transpiration. In SECHIBA, this is modelled by computing the water uptake function using only the dry soil height of the upper reservoir, when it is present, thus favouring evaporation by the upper part of the root system.

The approach to derive water uptake function may also be used to derive the $\beta$ function in the bucket model (Manabe, 1969) or the Warrilow scheme (Warrilow et al., 1986). To achieve this, the approximation of a homogeneous distribution of moisture and roots has to be made within the bucket. For the root stress, $\beta_{\text {root }}=M A X\left[r u u(z) / \mathrm{r} u u_{\text {crit }}, 1\right]$ has to be chosen (where $r u u_{c r i t}$ is a free parameter). This yields a water uptake function which is not independent of the depth of the reservoir.

In the following sections, it is shown that the current choice of parameters $\left(h_{t}=1 \mathrm{~m}\right.$ and $\left.c=0.8\right)$ is not optimal and that using observed values for $c$ improves SECHIBA behaviour. This approach to modelling the interactions between the soil hydrology and plant transpiration offers new possibilities. (i) The parameter $c$ can be varied from one vegetation type to the other the better to take diversity in root profiles into account. (ii) The soil moisture can be distributed within the column using a more complex function. (iii) The complexity of the root stress function can be increased.

The soil resistance to bare soil evaporation can be derived in the same way using a parameter $r_{t}$ which gives the resistance per metre of dry soil. Using this and the vertical distribution of soil moisture, the following relation is obtained:

$$
r_{s o i l}=h_{d} \cdot r_{t}
$$


A value of $33000 \mathrm{~s} \mathrm{~m}^{-2}$ for $r_{t}$ was chosen in SECHIBA (Ducoudré et al., 1993).

\section{EVAPORATION FLUXES}

\section{Transpiration}

Transpiration is computed in SECHIBA for each vegetation type $i$ in the grid-box:

$$
T R_{i}=\left(1-\frac{W_{c_{i}}}{W c \max _{i}}\right) U_{s_{i}} \rho \frac{q_{s}(T)-q_{a}}{r_{a}+r_{0_{i}}+r_{c_{i}}}
$$

where $W_{c_{i}}$ is the amount of water intercepted by the foliage, $1-\left(W_{c_{i}} / W_{c m a x}\right)$ is the fraction of the foliage available for transpiration (not covered by intercepted water). Transpiration is proportional to the gradient of humidity between air, $q_{a}$, and saturation at soil temperature, $q_{s}\left(T_{s}\right)$. Resistances limit evaporation by accounting for plant and aerodynamic effects: $r_{a}$ is the aerodynamic resistance and $r_{c i}$ is the canopy resistance (also called bulk stomatal resistance) (Ducoudré et al., 1993). The canopy resistance, $r_{c}$, depends on the net radiation, $S_{n}$, and the water vapour deficit of the air above the canopy, $\delta q$, and is inversely proportional to the leaf area index $(L A I)$ and the constant $k_{0}$ (Table 1), (Ducoudré et al., 1993; Jarvis, 1976).

$$
r_{c_{i}}=\frac{1}{L A I_{i}}\left[\frac{S_{n}+R_{0}}{S \downarrow}\right]\left[\frac{a+\lambda \delta q}{k_{0_{i}}}\right]
$$

in which the constant parameters $R_{0}, a$, and $\lambda$ have the following values: $R_{0}=125 \mathrm{~W} \mathrm{~m}^{-2}, a=23.10^{-3} \mathrm{~kg} \mathrm{~m}^{-3}$ and $\lambda=1.5$. The architectural resistance $r_{0}$ was introduced by Perrier (1975) to represent the aerodynamic conductance between the leaves and the top of the canopy. In the current version of the model, the same root profile is used in the computation of $U_{s}$ for all vegetation types. Consequently, only the various values of canopy resistance (Table 1) produce different values of transpiration.

\section{Bare soil evaporation}

Bare-soil evaporation, $E$, is calculated in SECHIBA as follows (Ducoudré et al., 1993):

$$
E=\rho U_{s} \frac{q_{s}\left(T_{s}\right)-q_{a}}{r_{a}+r_{\text {soil }}}
$$

The term $U_{s}$ is included in the first version of SECHIBA (Ducoudré et al., 1993) but it has no strong justification and its role is very limited, as seen in this simple example. For a dry soil height of $0.1 \mathrm{~m}, r_{\text {soil }}=3300$ $\mathrm{s} / \mathrm{m}$ and $U_{s}=0.92$ are detailed. This shows that the bare soil resistance is the main parameter controlling evaporation from bare soil.

\section{Interception loss}

When it rains, or when dew is forming, a film of water starts covering the leaves until the maximum storage capacity of the leaves is reached. The intercepted water is evaporated at a near potential rate but, at the same time, transpiration is suppressed over the fraction of wetted canopy. The amount of water intercepted by the foliage $\left(W_{c}\right.$, in $\left.\mathrm{Kg} \mathrm{m}^{-2}\right)$ is controlled by incident rainfall and interception loss. It is limited by the maximum capacity $\left(W_{c \max }\right.$ $=0.1 L A I)$. The evaporation of the intercepted water takes into account the different exposure to the air of the leaves in the canopy by including the architectural resistance $r_{0}$ (Ducoudré et al., 1993).

$$
I L_{i}=\left(\frac{W_{c_{i}}}{W_{c \max _{i}}}\right) \rho \frac{q_{s}\left(T_{s}\right)-q_{a}}{r_{a}+r_{0_{i}}}
$$

\section{GCM experiments with SECHIBA}

The present study is based on the analysis of 10 year inte-

\begin{tabular}{|c|c|c|c|c|c|}
\hline \multirow[t]{2}{*}{$i$} & \multirow[t]{2}{*}{ Vegetation } & \multicolumn{2}{|c|}{ LAI } & \multirow{2}{*}{$\begin{array}{c}r_{0} \\
\mathrm{~s} \mathrm{~m}^{-1}\end{array}$} & \multirow{2}{*}{$\begin{array}{c}k_{0} \\
\mathrm{~kg} \mathrm{~m} \mathrm{~s}^{-1}\end{array}$} \\
\hline & & summer & winter & & \\
\hline 1 & Tundra & 1 & 0 & 10 & $5.10-5$ \\
\hline \multirow{3}{*}{2} & Grassland & & & & \\
\hline & Latitude $>45^{\circ} \mathrm{N}$ & 2 & 1.5 & 0 & $30.10-5$ \\
\hline & Latitude $<45^{\circ} \mathrm{N}$ & 0 & 1 & 2 & $30.10-5$ \\
\hline 3 & Steppe & 2.5 & 1 & 2.5 & $28.10-5$ \\
\hline 4 & Savannah & 3.5 & 1.5 & 3 & $28.10-5$ \\
\hline 5 & Deciduous forest & 5 & 0 & 25 & $25.10-5$ \\
\hline 6 & Conifer & 4 & 3 & 25 & $12.10-5$ \\
\hline 7 & Tropical forest & 8 & 8 & 25 & $12.10-5$ \\
\hline
\end{tabular}
grations of the LMD General Circulation Model (GCM)

Table 1. Principal characteristics of the vegetation types. The LAI and $k_{0}$ are used in the calculation of the canopy resistance; $r_{0}$ is the architectural resistance. 
coupled to SECHIBA. The observed sea surface temperatures over the period 1978-1988 are used as boundary conditions for all experiments. Version cycle 6 of the LMD-GCM is used here with a horizontal resolution of $64 \times 50$ points (approximately $5.6^{\circ} \times 2.0^{\circ}$ in the equatorial regions) and 11 vertical levels. The LMD GCM is documented in Polcher and Laval (1994), Le Treut and Li (1991) and Sadourny and Laval (1984).

The experiments differ by the treatment of the soil hydrology/biosphere interaction. Various modifications made to SECHIBA will be explained later. A reference GCM simulation was performed with the land-surface scheme SECHIBA described above.

\section{THE REFERENCE EXPERIMENT ('REF')}

A detailed study of the reference version of SECHIBA (denoted REF) is conducted in a region on the eastern border of the Amazonian forest. This region is a representative example showing the model behaviour in tropical regions, where the surface is partially covered by tropical forest and savannah. The annual evolution of precipitation, soil moisture and transpiration is shown in Fig. 1a. The annual distribution of precipitation is characterized by a single rainy season from October to April and a single dry season from May to September. Compared to estimates (Hulme, 1992), the computed precipitation is too little, but the annual cycle is well represented. Model results in this region point out two dominant deficiencies of SECHIBA affecting most of the land surfaces in the GCM.

A strong correlation (0.995) between the annual cycle of savannah and tropical forest transpiration is noted in this region. SECHIBA computes a transpiration rate for each tile of each grid cell but, although the various canopies are characterized by different parameters (Table 1), their transpiration behaviours exhibit similar properties (Fig. 1a). In contrast, estimates show that savannah and tropical forest follow very different annual cycles for transpiration. While tropical forest evaporates at a nearly constant rate all year long (Shuttleworth, 1988a), savannah displays a more contrasted annual cycle with large values of transpiration during the rainy season and low values during the dry season (Wright et al., 1996). During wet months, Le Roux (1995) shows that transpiration $(T r)$ is close to potential evaporation $\left(E_{0}\right)$ for both tropical forest and savannah. From Shuttleworth estimations, he computes the ratio $T r / E_{0}$. Typically, $T r / E_{0}$ is equal to about 0.98 all year long for tropical forest, showing the stability of forest transpiration. For savannah, $T r / E_{0}$ varies from 0.93 during wet months to very low values during dry months. The model is not
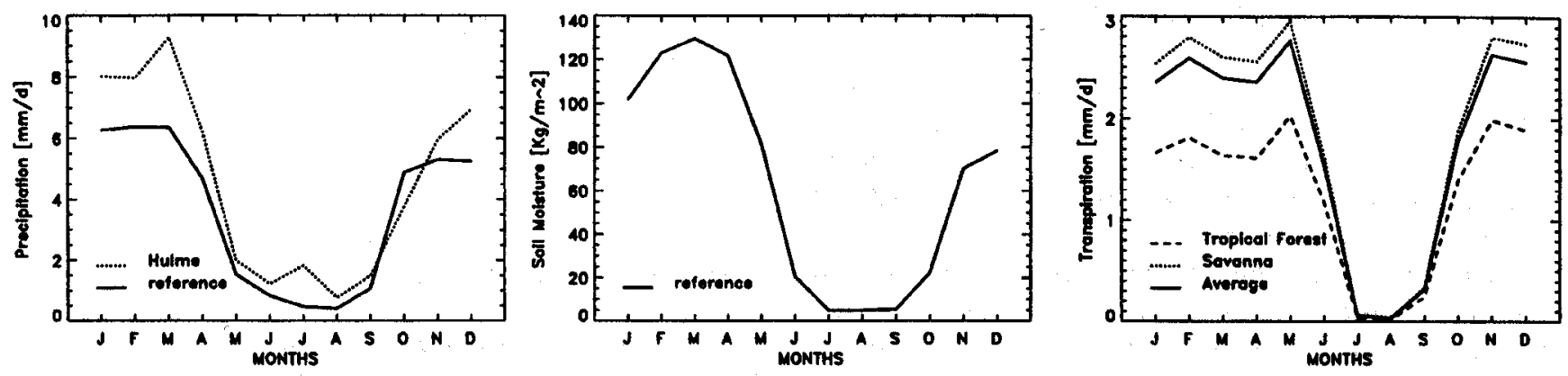

(a) REF
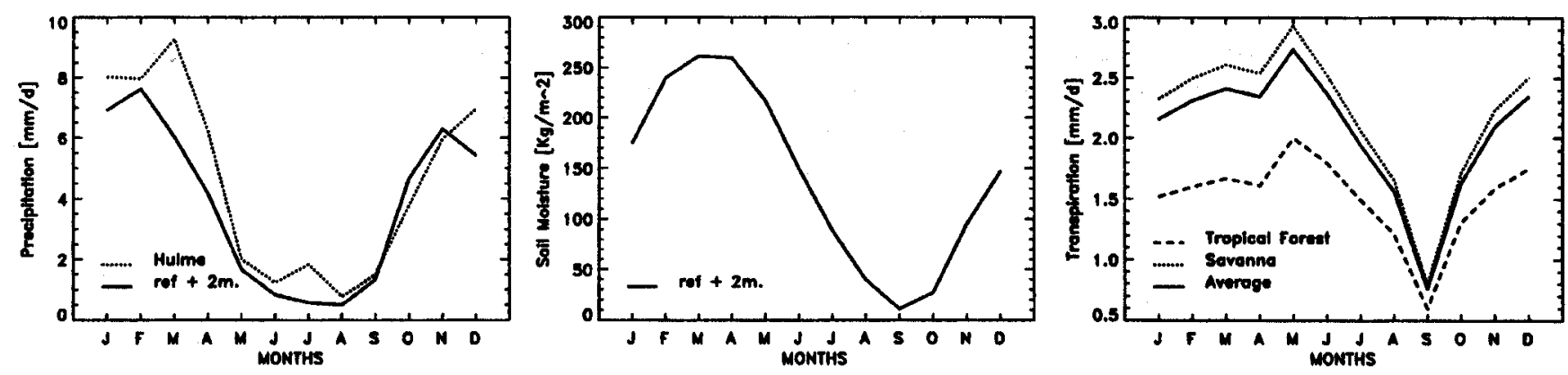

(b) REF+2m

Fig. 1. Results from the model in the eastern Amazonian forest region. The evolutions are averaged from 1979 to 1988. The three graphs on the top panel (a) show the results obtained mith the REF version of SECHIBA. The second panel (b) is devoted to the results from the version $R E F+2 m$. The annual cycle of precipitation estimated by Hulme is also represented. Precipitation and transpiration are expressed in mm/d, and Soil moisture in $\mathrm{Kg} / \mathrm{m}^{2}$. 
able to represent such differences in the annual cycle of transpiration between tropical forest and savannah, because all vegetation types within a mesh share the same soil moisture reservoir. Furthermore, the water uptake function in this reference simulation is the same for all the vegetation types; it does not take into account the different rooting profile of each plant. The map presented in Fig. 2 shows the correlation of the annual evolution of the transpiration between the two dominant vegetation types on each grid box of the GCM. Regions in blue correspond to areas where there is no vegetation. It should be noted that in some regions (Mexico, South Africa, Australia), the correlation is weaker because the LAIs of the two dominant vegetation types are very different. However, in most regions of the globe, the correlation of the annual evolution of transpiration is above 0.9 , indicating that different plants within the same grid-box have similar transpiration behaviour in the model. This emphasizes the need to use an individual hydrology for each vegetation tile in order to represent the different behaviour for the canopies.

Apart from this strong correlation, Fig. la shows that there is no transpiration in the model during the dry season. Due to low precipitation in June, July and August, the soil dries up and transpiration stops (Fig. 1a). Observations show, however, that the soil does not dry up totally and the deep water reserve allows the tropical forest to maintain a constant transpiration rate throughout the year (Hodnett et al., 1996a; Hodnett et al., 1996b; Wright et al., 1992; Shuttleworth, 1988a).

Soil moisture simulated by the GCM is too low on nearly all land surfaces. To illustrate this, Fig. 3 shows, for each grid box of the model, the number of days per year where total column soil moisture is below $5 \mathrm{~kg} \mathrm{~m}^{-2}$. This value was chosen arbitrarily to define soil drought. At this low soil moisture value, there is no water exchange between soil and atmosphere. Figure 3 shows that the soil is often dry over most of the land surfaces. Such low soil moisture values prevent the model from simulating correctly the inter-annual variability. The soil drought depicted in Fig. 3 might have several causes. For the Amazonian area, Fig. la shows that too low values of precipitation during the rainy season are not sufficient to explain the lack of transpiration; it is clear that the soil moisture capacity is too small for the model to accumulate enough water during the rainy season. Thus the soil water reserve is insufficient to allow the plants to transpire throughout the dry season. On the global scale, Table 2 shows that global land precipitation is overestimated by the GCM; hence, the large scale soil drought cannot be explained by low values of global precipitation. The water holding capacity of $150 \mathrm{~kg} \mathrm{~m}^{-2}$ is too low to give a correct representation of the annual cycle of evaporation as demonstrated by Rowntree (1995) and Robock et al. (1997) with the AMIP simulations. Milly and Dunne (1994) suggest that increased storage capacity enhances the ability of the soil to store water from periods of excess for later evaporation during the dry season.

\section{EXPERIMENT WITH AN INCREASED SOIL DEPTH ('REF+2M')}

To test this hypothesis, a ten year experiment is conducted with a version of SECHIBA modified to include two metres of soil depth. The water holding capacity of the soil is, therefore, doubled. This simulation is referred to as $\mathrm{REF}+2 \mathrm{~m}$. Doubling the soil depth may improve the representation of the dry season in most regions. At the same time, it does not affect the short time reaction of the upper soil moisture layer in SECHIBA. Increasing the total soil depth allows the soil to be exploited more deeply by the root systems.

The increased water accumulation during the rainy season, allows the plants to continue transpiring during the dry season, as illustrated in Fig. 1b. Figure 4 shows the averaged number of days per year with soil drought for the experiment REF $+2 \mathrm{~m}$. A comparison of Fig. 3 and Fig. 4 shows that this modification reduces the occurrence of

Table 2. World water balance in $\mathrm{mm} / \mathrm{d}$.

\begin{tabular}{|c|c|c|c|c|c|c|c|}
\hline \multirow[b]{2}{*}{$\mathbf{P}$} & \multicolumn{3}{|c|}{ Land } & \multicolumn{4}{|c|}{ Ocean } \\
\hline & $\min$ & $\begin{array}{c}\mathrm{E} \\
\text { mean }\end{array}$ & $\max$ & $\mathbf{R}$ & $\mathbf{P}$ & $\mathbf{E}$ & Source \\
\hline 2.04 & & 1.32 & & 0.73 & 2.92 & 3.22 & (Baumgartner and Reichel, 1975) \\
\hline 2.19 & & 1.23 & & 0.96 & 3.48 & 3.84 & (Budyko, 1978) \\
\hline 2.19 & & 1.33 & & 0.86 & 3.48 & 3.84 & (Korzun et al., 1974) \\
\hline 1.97 & & 1.31 & & 0.66 & 3.02 & 3.29 & (Chahine, 1992) \\
\hline 2.99 & 1.56 & 1.60 & 1.61 & 1.40 & 2.87 & 3.52 & Reference \\
\hline 3.01 & 1.65 & 1.66 & 1.68 & 1.35 & 2.89 & 3.51 & $\mathrm{REF}+2 \mathrm{~m}$ \\
\hline 2.97 & 1.56 & 1.62 & 1.64 & 1.36 & 2.89 & 3.52 & EXP1 \\
\hline 3.02 & 1.52 & 1.57 & 1.59 & 1.45 & 2.85 & 3.52 & EXP2 \\
\hline
\end{tabular}

P: Precipitation, E: Evaporation, R: Runoff. 


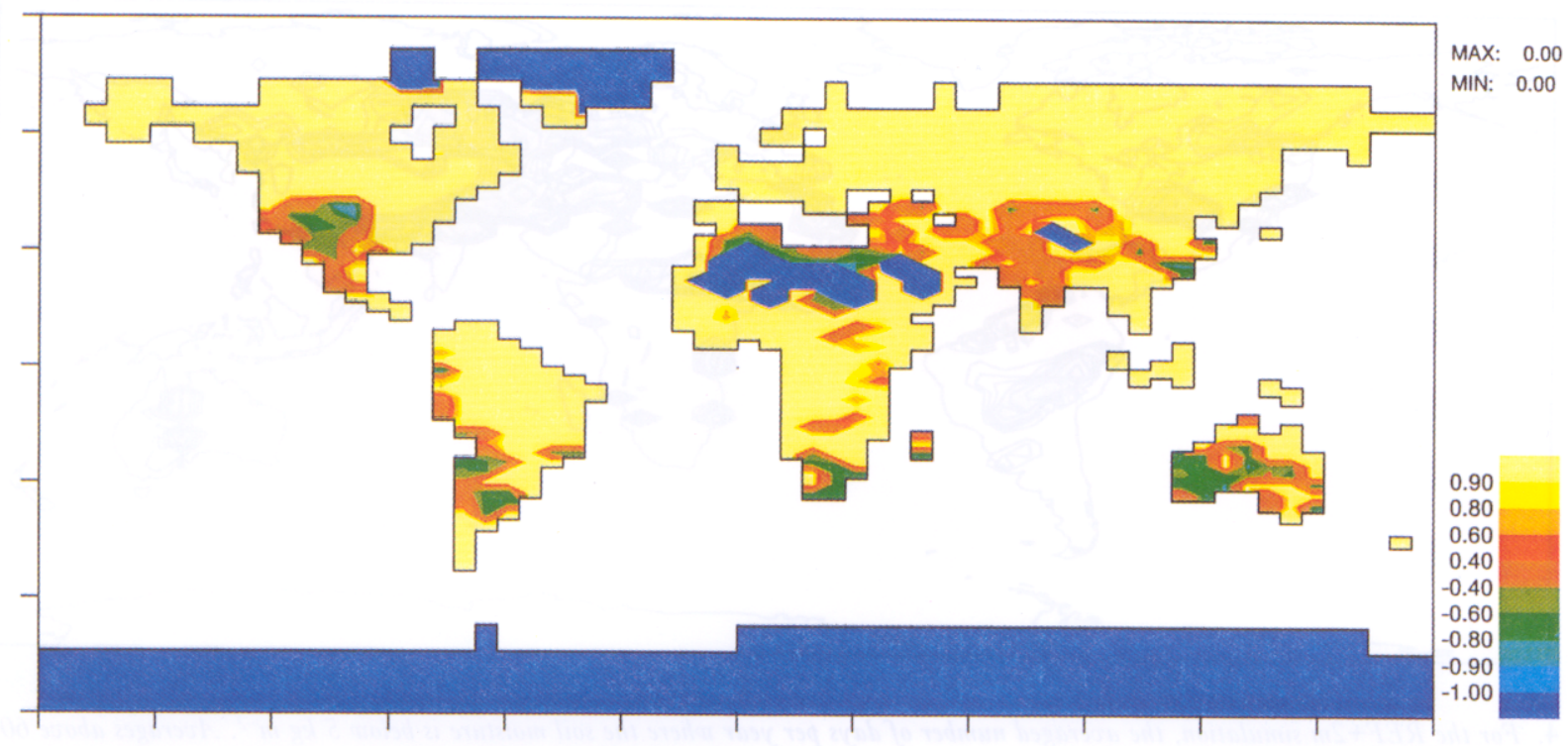

Fig. 2. Reference simulation. Map of the correlation coefficient between the annual evolution of the computed transpiration for the two principal vegetation types present on each mesh (the blue regions correspond to the site where there is no vegetation).

drought in the model. Such a change in soil moisture leads to modification in the energy fluxes' repartition.

France is chosen to continue the analysis. It is located in middle latitudes where summer is associated with large values of solar radiation and evapotranspiration. Estimates of the evaporative fraction (equal to the ratio of latent heat flux to the sum of latent and sensible heat fluxes) are above $50 \%$ over France during summer (Choisnel et al., 1995; Henning, 1989). The partition of surface fluxes in the REF simulation corresponds to an evaporative fraction below
$20 \%$ for the three summer months. This underestimate of evaporative fraction in REF has two causes: (i) too high an estimate of sensible heat flux linked to too high a net surface radiation (ii) very low rate of evapotranspiration in summer exacerbates the overestimation of sensible heat flux. The low estimate of evapotranspiration is due to excessive soil dryness in summer. There may be a number of reasons for the low soil water content in summer: insufficient precipitation in summer and the inability of the soil to store sufficient water during the rainy season for release

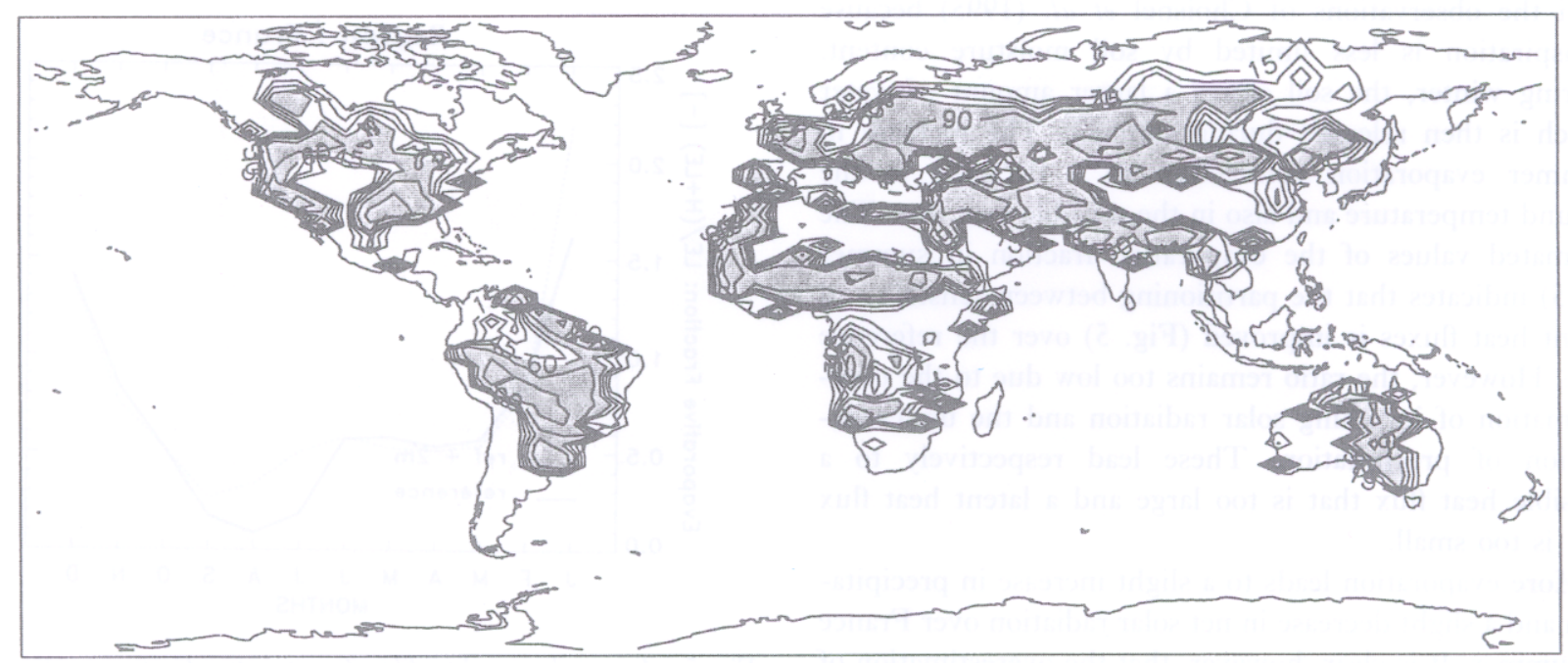

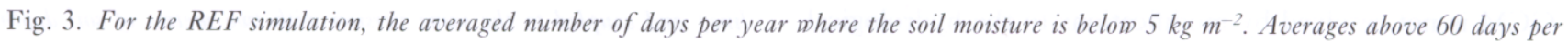
year are shaded. 


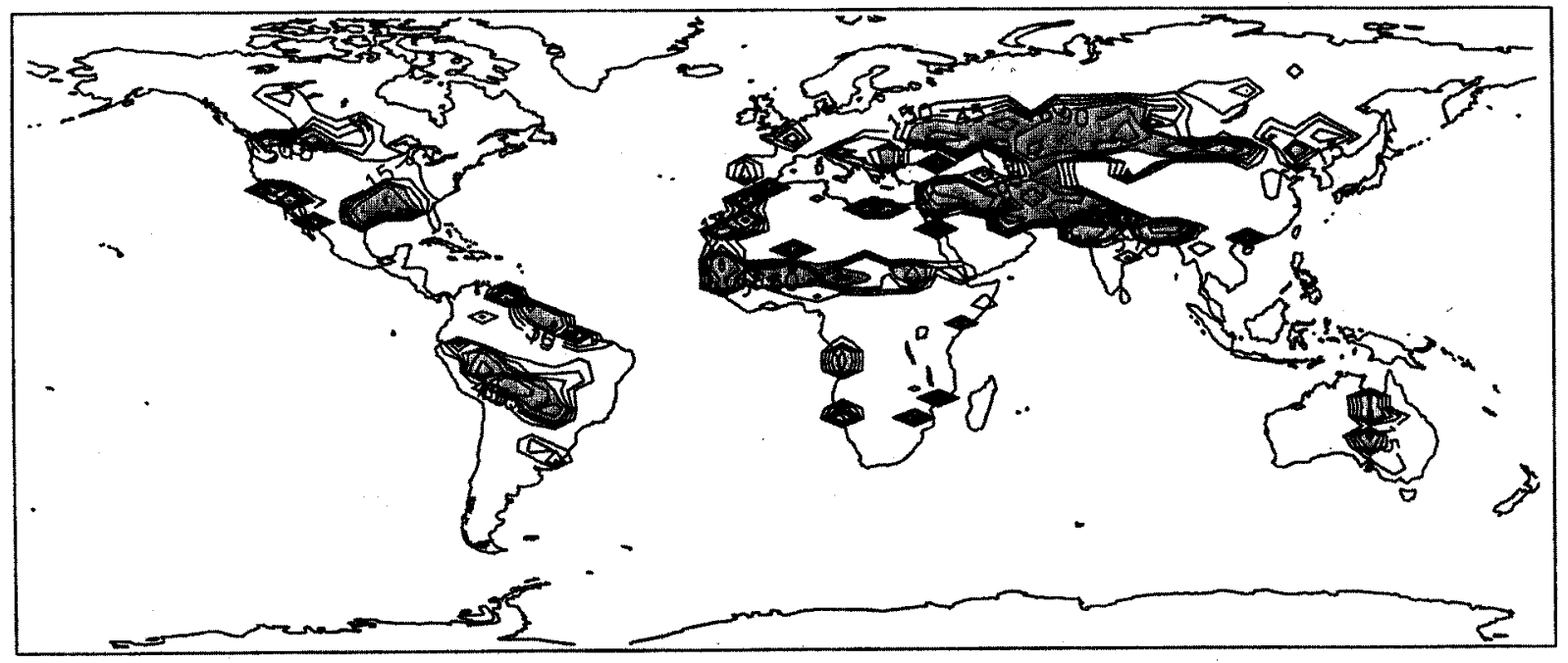

Fig. 4. For the $R E F+2 m$ simulation, the averaged number of days per year where the soil moisture is below $5 \mathrm{~kg} \mathrm{~m}^{-2}$. Averages above 60 days per year are shaded.

during periods of shortage. Furthermore, the excess of solar radiation leads to the soil drying too quickly in spring instead of summer. The overestimation of net solar radiation at the surface is attributed to a poor simulation of cloud cover and of clear sky radiation, and to the absence of aerosols in the model (Bony et al., 1992). The too low estimates of evaporation during summer increase calculated surface temperature. This deficiency of the model had already been described in other GCMs where summer is too dry, and hence too warm, due to an overestimation of incoming solar radiation (Viterbo, 1994; Wild et al., 1995).

In the experiment with two metres of soil depth, $R E F+2 m$, the summer transpiration is in better agreement with the observations of Choisnel et al. (1995) because transpiration is less limited by soil moisture content. During winter, the soil stores a larger amount of water which is then released during summer. The increase in summer evaporation contributes to a decrease in the ground temperature and also in the sensible heat flux. The estimated values of the evaporative fraction in summer $(0.35)$ indicates that the partitioning between sensible and latent heat fluxes is improved (Fig. 5) over the reference case. However, the ratio remains too low due to the overestimation of incoming solar radiation and the underestimation of precipitation. These lead respectively to a sensible heat flux that is too large and a latent heat flux that is too small.

More evaporation leads to a slight increase in precipitation and a slight decrease in net solar radiation over France in summer. It is clear, however, that the overestimation of solar radiation and underestimation of precipitation in the GCM is not resolved by modifications to the hydrological part of the model.
With two metres of soil depth, the annual cycle of evaporation is more realistic, and the total annual evaporation is in good agreement with the estimates of Choisnel in this region. The global mean evaporation over land is overestimated in the simulation REF $+2 \mathrm{~m}$ (see Table 2). When compared to estimates (Chahine, 1992; Budyko, 1978; Baumgartner and Reichel, 1975; Korzun et al., 1974), the global mean evaporation over land is already overestimated in the REF simulation. In the $\mathrm{REF}+2 \mathrm{~m}$ experiment this bias is increased due to an insufficient control of transpiration by the soil-plant system. Milly and Dunne (1994) have quantified the sensitivity of continental evaporation

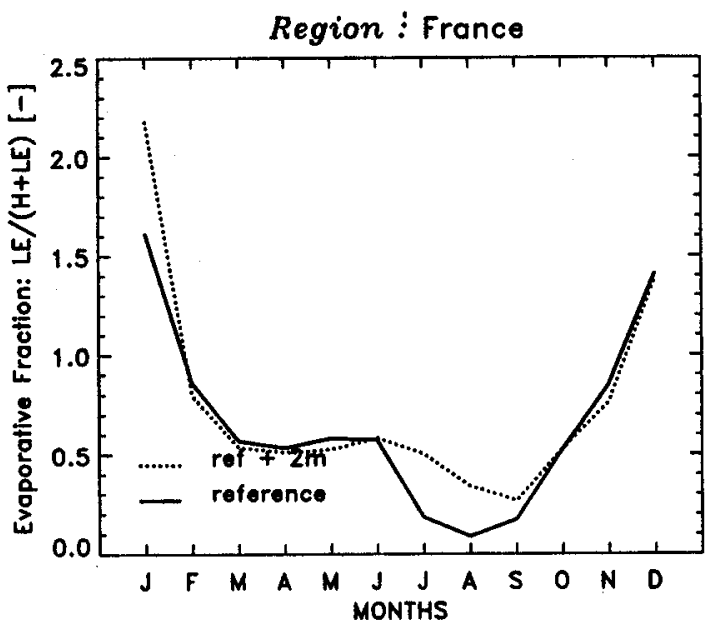

Fig. 5. Averaged annual profiles of evaporative fraction computed by the LMD-GCM coupled to the REF version of SECHIBA (solid line) and coupled to the same version with two metres of soil depth (dotted line). 
to soil moisture storage capacity. They found that global annual evaporation from land increases by about $70 \mathrm{~mm}$ $\mathrm{y}^{-1}$ when the soil water storage capacity is doubled, providing the value remains smaller than $600 \mathrm{~kg} \mathrm{~m}^{-2}$. Table 2 shows that the sensitivity of the LMD GCM to changes in soil water storage capacity is weaker: continental evaporation increases by about $21.6 \mathrm{~mm} \mathrm{y}^{-1}\left(0.06 \mathrm{~mm} \mathrm{day}^{-1}\right.$ in the table) when soil water capacity is doubled. This may be explained by the fact that SECHIBA includes a more complex hydrological limitation of evaporation (the water uptake function $U_{s}$ ) than the bucket scheme used by Milly and Dunne (1994). The overestimation of evaporation may be attenuated by a more accurate representation of root profile for each plant.

\section{Modifications to SECHIBA}

\section{ROOT PROFILE}

Knowledge of the density and distribution of roots in the soil is critical in modelling the water uptake by plants. Root density determines the plant's ability to extract water from the soil. Thus, plant transpiration is linked to root distribution. The plants with deepest rooting profiles are likely to maintain larger transpiration rates during dry periods while plants with shallowest rooting profiles may strongly decrease their transpiration. Jackson et al. (1996) have synthesized data on root distribution densities and biomass for major terrestrial vegetation types. Their study shows that Tundra, grass and boreal forest present the shallower rooting profiles. Tropical forest shows a deeper rooting profile, and a greater averaged root biomass. For tropical forests, estimates show that during the dry season, water may be extracted from a soil layer more than eight metres deep (Canadell et al., 1996; Nepstad et al., 1994). Hodnett et al. (1996a) shows that the proportion of water taken up from below 3.6 metres depth at the end of the dry season is about $\mathbf{5 0 \%}$ for tropical forest. Moreover, several root length estimates are available (Fig. 6, top panel) for savannah, grass, and steppe (Le Roux, 1995; Akpo, 1992; Grouzis, 1988), and for forests (Nepstad et al., 1994; Kalisz et al., 1987; Gale and Grigal, 1987). Most of these estimates are obtained using an exponential distribution for root length fitted with a constant $c$ (see Eqn. 1) which depends only on the vegetation type. An alternative method is based on an asymptotic function for cumulative root fraction from the soil surface. Here as well, a vegetation dependent parameter can be used to fit the asymptotic function. Both methods yield a very similar classification of vegetation types by their root profile parameters although they are based on independent datasets collected on different soils. This indicates that the relations between the parameters and the vegetation types are robust.

In SECHIBA, the calculation of the water uptake function is based on the exponential formulation of the root profile (see Eqns. 1, 2 and 3). According to the study of
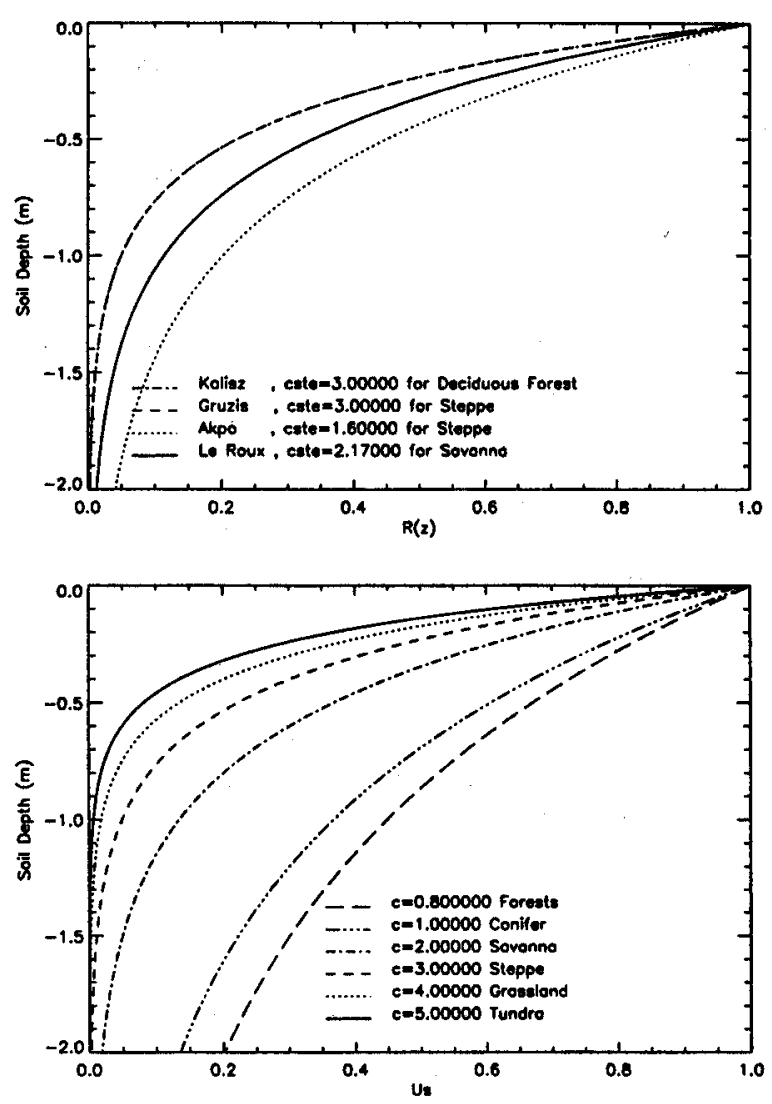

Fig. 6. Top panel: some observed normalized root density profiles. Lomer panel: Water uptake function, $U_{s}$, for each canopy. These profiles depend on the depth of dry soil and on the value of the constant $c$. The chosen values for $c$ corresponding to each vegetation type are indicated.

Le Roux (1995) the formulation which represents the root length profile is better adapted to modelling water uptake by roots. But the single value of the constant $c$ used in SECHIBA for all the vegetation types does not allow for the representation of the different soil-plant-atmosphere water fluxes due to the different root systems.

In an attempt to depict various rooting profile distributions, one value of the constant $c$ is attributed, in the modified versions of SECHIBA, to each type of canopy (Fig. 6, bottom panel). The values of $c$ for plants with small root systems correspond to the fitted value of $c$ for estimated root length. The savannah modelled is shallow rooted. Other types of savannah which are a complex mixture of shrubs and grasses are not represented in the model. As only two metres of soil are available in SECHIBA, values of $c$ smaller than those estimated must be specified for tropical forest to simulate the deep water extraction by roots.

Different root profiles lead to different water uptake functions, so that SECHIBA is now able to simulate roughly one hydrological stress for each vegetation type. Thereby, larger contrasts in transpiration between types of canopies may be simulated. 
ONE HYDROLOGICAL SOIL COLUMN FOR EACH VEGETATION TYPE

For each vegetation type present in the mesh, a soil moisture column is selected and treated independently. As with transpiration, interception and soil precipitation, soil moisture and runoff are computed for each tile in the grid square. This approach assumes that the spatial distribution of vegetation is strongly heterogeneous because interaction is not possible between the different soil tiles. A well mixed vegetation distribution, in which all plants draw moisture from the same reservoir, would be better represented by the old scheme where they shared a single hydrology (Shuttleworth, 1988b).

Water exchanges are allowed between the columns in the lower layer of the soil. This transfer of water is determined by a time constant for diffusion between different columns of a mesh, and it depends on the degree of heterogeneity in the soil moisture distribution. Horizontal water exchanges between the columns are not allowed for the upper layer which works on short time scales and is thus strongly linked to the vegetation distribution. The choice of time constant for the lateral diffusion is crucial for the interaction between the different tiles in a mesh. Moreover, it is the single parameter that determines the degree of heterogeneity of the soil moisture distribution. In order to test and compare two extreme cases of spatial distribution of soil moisture heterogeneity, two simulations were performed with the multicolumn version of SECHIBA.

(i) The situation where all the columns have the same amount of water in the lowest layer corresponds to a homogeneous soil moisture repartition. In such a case, the surface layer is different for each vegetation type whereas all columns have the same amount of water in the deep soil layer. This approach is well adapted to represent a well mixed vegetation distribution. This experiment is referenced as EXP1.

(ii) In contrast, the opposite extreme where each soil column is absolutely independent of the others, corresponds to a heterogeneous partitioning of soil moisture. In this case, water transfer between different soil columns is negligible. For each biome, the hydrological processes in the soil are computed independently. This experiment is referred to as EXP2.

These experiments are carried out for the same period and using the same initial state as the REF and REF $+2 \mathrm{~m}$ experiments. In both experiments, a two layer soil column of depth equal to two metres is associated with each vegetation type. In addition, the various rooting depths are accounted for as explained earlier.

\section{Experiments with the modified version of SECHIBA}

For each of the four simulations (REF, REF $+2 \mathrm{~m}, \mathrm{EXP} 1$, EXP2), the mean annual cycles of precipitation averaged over the 10 years of the integration, soil moisture and transpiration are shown for the Amazonian region in Fig. 7a. More information is also represented in Fig. $7 b$ and $c$, for EXP1 and EXP2, and in Fig. $1 a$ and $b$, for REF and $\mathrm{REF}+2 \mathrm{~m}$. The four simulations present a similar annual distribution of precipitation, characterized by one rainy season extending from October to March and one dry season from May to September.

Firstly the results of the experiments EXP1 and EXP2 are described. Then, values obtained using the simple version of SECHIBA ( $\mathrm{REF}$ and $\mathrm{REF}+2 \mathrm{~m}$ ) are compared with those from the two modified versions (EXP1 and EXP2) in the Amazonian region.

\section{EXP1: STRONG DIFFUSION BETWEEN THE DEEP SOIL LAYERS}

In the first experiment (EXP1), different soil columns have a similar amount of water (Fig. 7b). However, Fig. 7b shows that very different transpiration rates are simulated for savannah and tropical forest.

As soon as the dry season starts in April-May, the ecosystem with a shallow root distribution (savannah here) shows a rapid decrease in transpiration, whereas the biome more deeply rooted (tropical forest here) is able to sustain an high evaporation rate. The tropical forest maintains a transpiration rate above $2 \mathrm{~mm} \mathrm{~d}^{-1}$ all year while the transpiration of the savannah drops to below $1 \mathrm{~mm} \mathrm{~d}^{-1}$ during the three dry months of July, August and September. Then, the soil water amount decreases and the remaining water available for plants is located in the deep soil layer shared by both forest and savannah columns. The values chosen for the constants, $c$, enable water uptake to be larger for forest than for savannah (Fig. 6).

With less evaporation from the savannah tile, soil moisture decreases more slowly in EXP1 than in REF or $\mathrm{REF}+2 \mathrm{~m}$. Since some water is kept in the lowest soil layer during the dry season, the tropical forest can transpire throughout the dry season. Forest transpiration is maximum during the dry season because more energy is available at the surface, and less intercepted precipitation covers the foliage. The behaviour produced in EXP1 is consistent with estimates by Le Roux (1995) and Shuttleworth (1988a) which show that tropical forest maintains transpiration during the dry season while transpiration from savannah decreases during dry season.

To the best of the authors' knowledge, no measurements of surface fluxes, available over savannah and tropical forest, are close enough to consider that they share the same climate. The ABRACOS (Anglo-BRazilian Amazonian Climate Observation Study) field campaigns have been carried out from 1990 to 1993 in Amazonia with the aim of estimating the differences in the vegetation-climate interaction between tropical-forest and pasture (Gash et al., 1996; Wright et al., 1996). From these campaigns, measured fluxes are available for some sites of Amazonia 

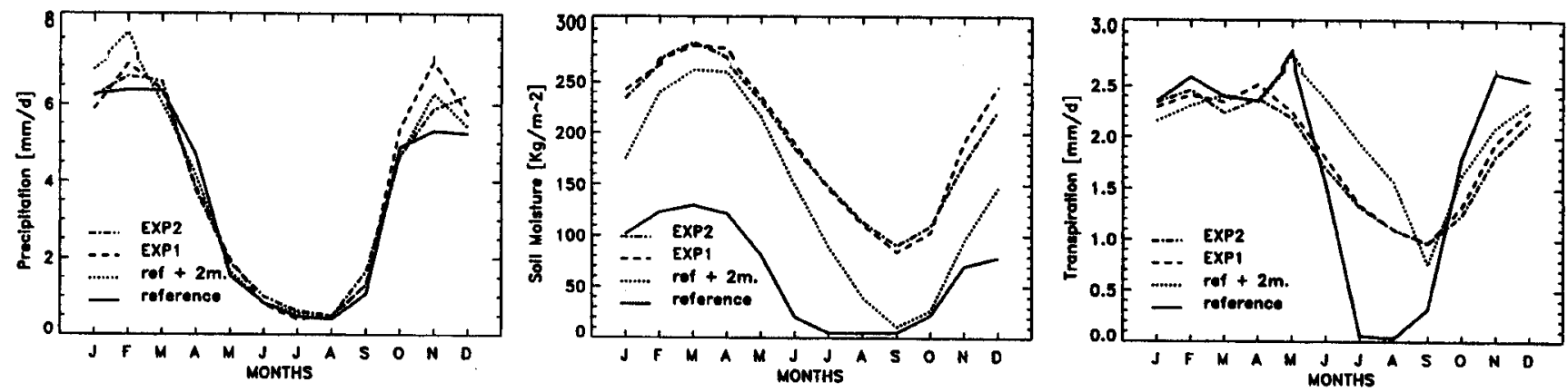

(a) All Simulations
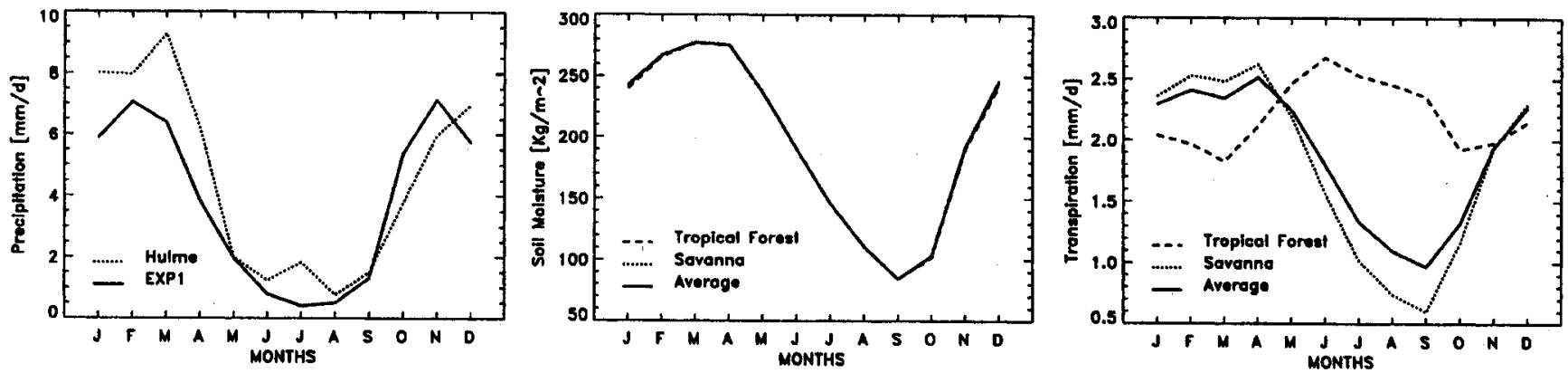

(b) EXP1
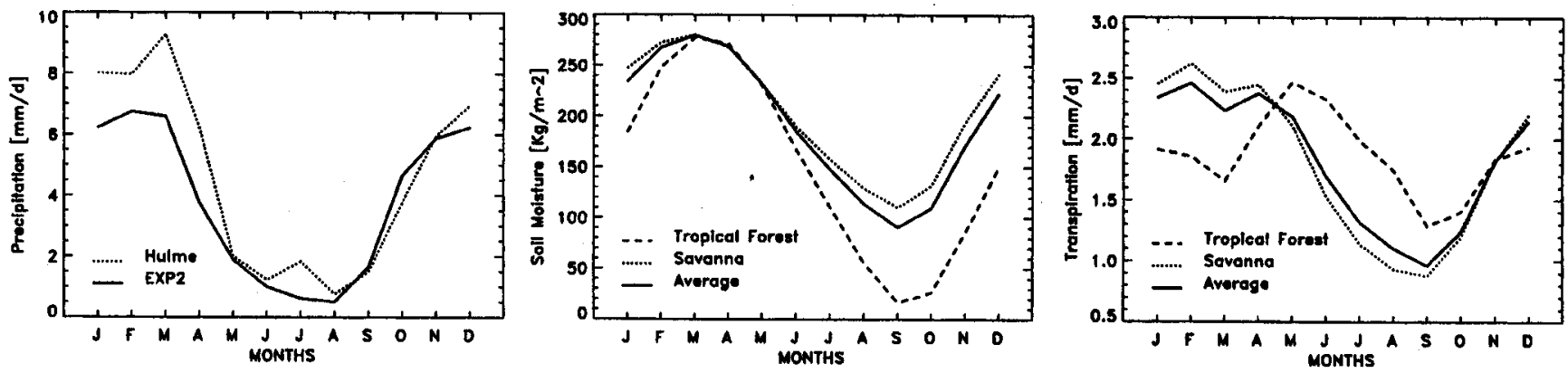

(c) EXP2

Fig. 7. Results from the model in the east Amazonian forest region. The three graphs on the top row (a) represent a comparison between the different versions of SECHIBA. The results from EXP1 are shown on the middle row (b), and those from EXP2 on the bottom row (c). Precipitation and transpiration are expressed in $\mathrm{mm} \mathrm{d}^{-1}$, and Soil moisture in $\mathrm{kg} \mathrm{m}^{-2}$.

over pasture and tropical forest, and range in duration from six weeks to three months. Figure 8 shows the measured precipitation on the top row and evapotranspiration on the lower row at the site of Ji-Paraná. The left column corresponds to the campaign ' $\mathrm{M} 4-5$ ' conducted from April to July 1993, and the right column shows the measurements obtained during the campaign 'M3' during August, September and October 1992. Combining the observations from M4-5 and M3 gives a good impression of the evolution of evaporation during the dry season. During the period where precipitation decreases (Fig. 8a, left graph), the tropical forest (full line) keeps large values of evapo- transpiration while the pasture (dotted line) decreases its evapotranspiration (Fig. 8b). From August to September, Fig. 8 shows that the increase of precipitation leads to an increase of pasture evapotranspiration while forest evapotranspiration increases only slightly (Fig. 8b).

These observations cannot be compared directly to the GCM outputs as the location of the GCM region studied here does not correspond to the Ji-Paraná site (where vegetation cover is exclusively tropical forest in the model). Nevertheless, pasture and savannah are both shallower rooted than tropical forest. The observed contrast between tropical forest and pasture indicates clearly that 

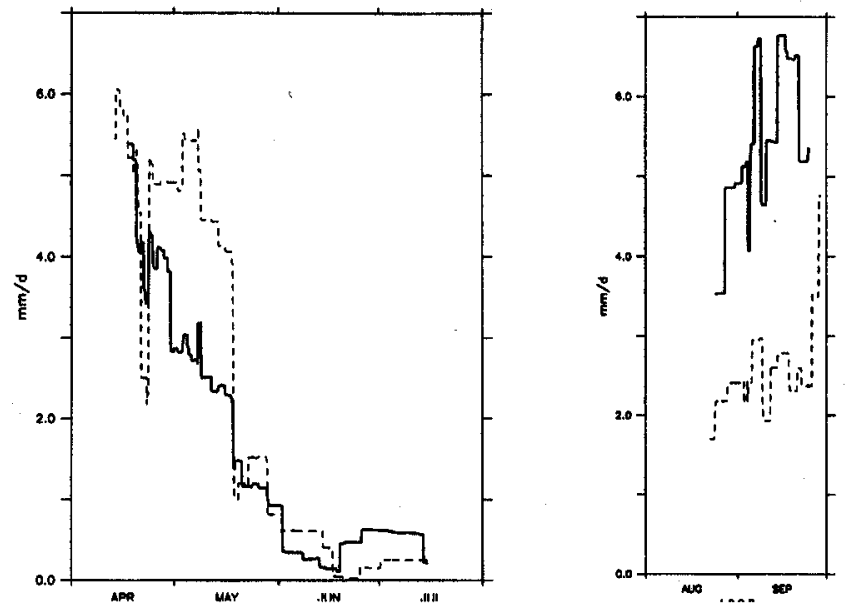

(a) Preciptation
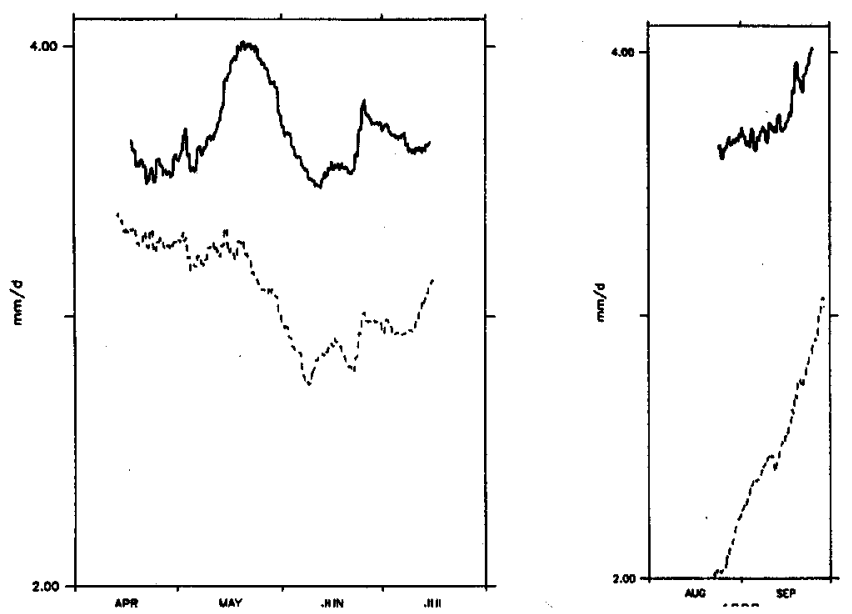

(b) Evaporation

Fig. 8. Measured fluxes from the ABRACOS campaigns at the site of Fi-Paraná. The lefthand graphs correspond to the campaign 'M4-5' conducted from April to Fuly 1993, and the righthand graphs show the measures obtained during the campaign 'M3' during August, September, October 1992. Measured precipitation is on the top row (a) and evapotranspiration on the lower row (b). Dotted lines correspond to measures over pasture, and full lines to forest.

the differences in the modelled fluxes between tropical forest and savannah is realistic. The larger values of measured fluxes are due to the contribution of interception-loss which is not shown in the model's results (Fig. 7).

The EXP1 results show that the water uptake function is critical for the computation of transpiration. This demonstrates that accounting for various root system profiles allows a better representation of the behaviour of mixed tropical forest and savannah. Consequently, the correlation between the annual cycle of transpiration for the two major plant types in each mesh is lower in EXP1 than in the REF simulation (Fig. 9 and Fig. 2). Another consequence of the weaker savannah water uptake is the reduced frequency of soil drought. The chosen root profiles lead generally to smaller values of the water uptake function in most regions. Thus, the occurrence of drought decreases in the version of the model which accounts for different root profiles (not shown).

\section{EXP2: NO DIFFUSION BETWEEN THE DEEP SOIL LAYERS OF THE DIFFERENT TILES}

Figure $7 \mathrm{~b}$ shows that EXP2 gives different soil moisture values for each tile. Different water contents associated with different rooting profile should produce very different evolutions of transpiration for savannah and forest. However, Fig. $7 \mathrm{~b}$ and $\mathrm{c}$ exhibits a stronger correlation of the annual cycle of transpiration between savannah and forest in EXP2 than in EXP1 (respectively 0.41 and $-0.53)$.

From May to September, savannah exhibits weak transpiration due to a shallow root system and so some moisture remains in its deep soil layer. As there is no water transfer between different tiles, the water stored remains accessible only to the savannah. Thus, savannah can transpire during the dry season, but, owing to the parameterization of the root profile, the hydrological stress is large and transpiration is limited.

For tropical forests, the large transpiration is made possible by a deep root system which can empty the entire soil column. Because the two soil columns are absolutely independent, the forest soil moisture decreases strongly from May to September. Thus, the forest transpiration decreases in the dry season and reaches its minimum value $\left(0.85 \mathrm{~mm} \mathrm{~d}^{-1}\right)$ in September. When the rainy season restarts, more rainfall is needed to recharge the soil in forest tiles (see Fig. 7c), since more water was extracted during the dry season. This is emphasized in the model as the forest intercepts a larger fraction of the incoming rainfall than savannah. Such behaviour is well described by Hodnett et al. (1996a) from measurements of soil water storage variations under pasture and tropical forest at the three sites of ABRACOS campaigns in Amazonia.

In this experiment, the forest hydrological stress is due to the water availability. The savannah hydrological stress is due to the shallow root system. Accordingly, the source of transpiration decrease is different for each tile, but there is a greater correlation between the transpiration of the different vegetation types in EXP2 than in EXP1. In contrast, the correlation of soil moisture is weaker in EXP2.

\section{Discussion}

To compare fluxes averaged over a whole grid box for each of the four experiments (Fig. 7a), an averaged value is considered for precipitation, soil moisture and transpiration. The difference between REF simulation and all the others is the soil water capacity. The atmospheric forcing is similar during the dry season, but soil moisture and transpi- 


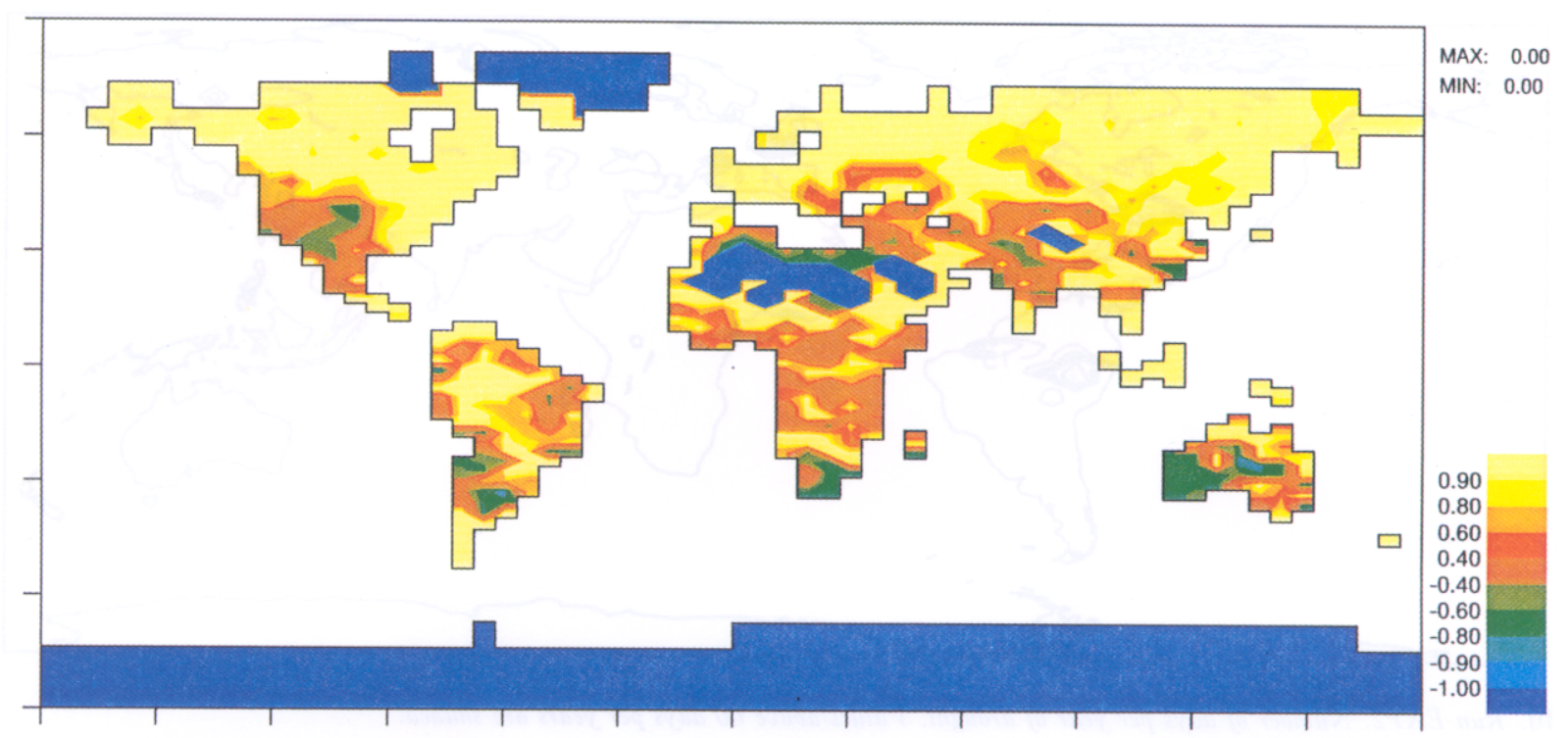

Fig. 9. Run EXP1. Map of the correlation coefficient between the annual evolution of the computed transpiration for the two principal vegetation types present on each mesh (the blue regions correspond to sites where there is no vegetation).

ration responses are very different depending on the simulation considered. In the three experiments in which soil is two metres deep, transpiration is larger during the dry season because of the greater amount of water accumulated in the soil during the wet season. Yet, as shown by results from $\mathrm{REF}+2 \mathrm{~m}$, increasing the soil depth only, without altering the rooting profile, leads to an overestimation of transpiration in the first months of the dry season, so that the soil dries too quickly.

The results also suggest that taking into account the root profile for each plant is crucial to model transpiration. Figure 7a shows clearly that the two experiments in which variable root density profile is taken into account exhibit similar annual averaged profiles for transpiration. As soon as the dry season starts, the transpiration begins to increase in REF and REF $+2 \mathrm{~m}$ whereas it decreases in EXP1 and EXP2. The increase in transpiration in May in REF and $\mathrm{REF}+2 \mathrm{~m}$ is explained by the increase in incoming solar radiation in the early dry season while water is still available for transpiration. In EXP1 and EXP2 only tropical forest increases its transpiration because of enhanced solar radiation. The savannah does not follow this behaviour due to its shallower rooting system. The increase of hydrological stress during the dry season overrides the increase in solar radiation at the surface. In REF and $R E F+2 m$ simulations, transpiration was controlled mainly by energy availability. The representation of the root profiles used in EXP1 and EXP2 allows the soil hydrology to have a more important control on transpiration of savannah. Hence, the average transpiration decreases in May in the experiments where SECHIBA has variable root density profiles.

It should be noted that in EXP1 and EXP2, savannah transpiration dominates from November to April while forest transpiration is larger from May to October. This behaviour is realistic as savannah displays a more contrasted annual cycle of transpiration than forest (Le Roux, 1995). During the rainy season, the dry soil depth in the model is small; thus the water uptake function is close to one for both forest and savannah as illustrated by the Fig. 6 , bottom panel. In this case, the transpiration depends principally on the vegetation characteristics summarized in Table 1. The weaker architectural resistance in savannah leads to a larger transpiration rate than for forest. During the dry season, the depth of dry soil is larger and the water uptake function becomes crucial for the calculation of the transpiration. The shallower root system leads to a smaller water uptake function for savannah than for forest; thus savannah transpiration is more limited than forest transpiration during the dry season.

The global water balances for each simulation and for some available estimates are summarized in Table 2. As explained previously, the GCM coupled to the REF version of SECHIBA simulates large values of continental evaporation. Increasing the soil depth in $\mathrm{REF}+2 \mathrm{~m}$ exacerbates this deficiency as already pointed out by Milly and Dunne (1994). But keeping two metres of soil depth and taking into account differences in root distribution leads to a reduction of global evaporation over continental areas because of stronger control of transpiration by hydrology. Moreover, continental evaporation is weaker when soil moisture heterogeneity is at a maximum as in EXP2. In this case, some plants reduce their transpiration due to a lack of water available in their soil column. In contrast, stronger horizontal diffusion in EXP1 allows plants to evaporate because the deep reservoir is common for the whole mesh. The first part of the study confirms the 


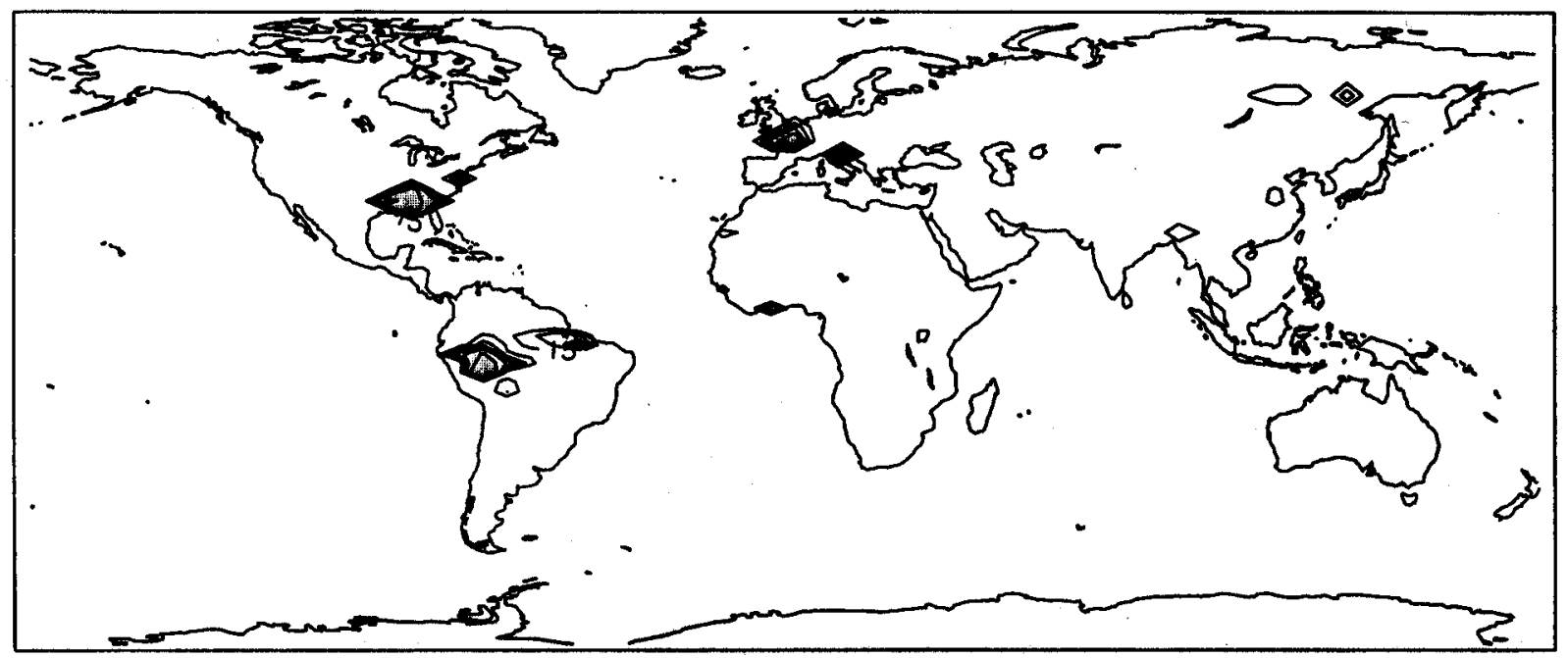

Fig. 10. Run EXP2. Number of days per year of drought. Values above 60 days per years are shaded.

results of Milly and Dunne (1994). However, this result is complemented by showing that an improved representation of the hydrological control on evaporation limits the impact of increasing the soil moisture reservoir on the hydrological cycle.

The drought frequency is also studied for each simulation. The results shown earlier demonstrate that increasing the soil depth reduces the dryness in the model (Figs. 3 and 4). Introducing the root density profile in the parameterization of the transpiration reduces the drought in the model further. Figure 10 presents drought maps for EXP2. The dry regions are far less extensive in EXP2 than they are in EXP1 (not shown). With a maximum soil water heterogeneity in EXP2 due to independent soil moisture tiles, there may remain in each mesh a tile, corresponding to a plant with a shallowly rooted system, in which soil moisture content is large.

Another interesting issue is the impact of the model modifications on simulation of the inter-annual variability. To this end, a preliminary statistical study was conducted for the inter-annual variability of the soil moisture and latent heat flux. Anomalous time series of monthly mean soil moisture were computed at each grid point by subtracting the individual monthly mean soil moisture values from the 10 year averaged monthly mean soil moisture values. The same procedure was performed for latent heat flux. The standard deviation of the anomaly represents the inter-annual variability. Figure 11, top panel, shows a map of the difference between the standard deviation computed in REF $+2 m$ and REF simulation for soil moisture. This map represents the spatial distribution of the change in inter-annual variability of soil moisture when the soil depth increases. The other map shown in Fig. 11 (bottom panel) represents the differences between the amplitude of the soil moisture annual cycle simulated in $\mathrm{REF}+2 \mathrm{~m}$ and REF. The map on the top panel shows that the soil moisture inter-annual variability increases strongly in most regions when soil moisture capacity increases. The deeper soil allows increased water exchange between the soil and the atmosphere. With a soil depth of one metre, the annual cycle of soil moisture, in most regions, varies from full during the rainy season to empty during the dry season. Such a cycle does not allow large inter-annual variability. Maps in Fig. 11 are correlated (with a confidence level of 0.99 ) and show that the increase in inter-annual variability is linked to an increase in amplitude of the annual cycle. When soil moisture increases, the amplitude of the annual cycle is larger, and the variability increases. This is attenuated when the different root length profiles are taken into account. The differences between the soil moisture interannual variability and the amplitude of the annual cycle between EXP1 and the REF simulation are less. The chosen values of the constant, $c$, in EXP1 are larger than those used in the REF version of SECHIBA (except for forests which have the same value). A larger value of this constant reduces the amplitude and variability of soil moisture content. For evaporation, the inter-annual variability and the amplitude of the annual cycle are less influenced by hydrological modification. Evaporation is dependent not only on soil hydrology, but also results from complex interactions between the atmosphere and soil hydrology. The amplitude of the annual cycle of evaporation decreases when soil water capacity is doubled. For evaporation, the decrease in amplitude of the annual cycle is correlated (with a confidence level of 0.99 ) with a decrease in its inter-annual variability (not shown). The annual cycle is smaller with a larger soil moisture content capacity. This is due to the fact that during the dry season, evaporation does not reach zero. This difference between $R E F$ and $R E F+2 m$ is also well illustrated by the example of eastern Amazonian forest in Fig. 7a. 


\section{Conclusions}

This paper presents an improved version of the land surface scheme SECHIBA. The analysis has focused on the interactions between the sub-grid scale variabilities of vegetation, soil moisture and root profiles which enhance the control of evapotranspiration by the soil-plant system.

To begin with, the capacity of the soil to hold water is doubled. This modification avoids too frequent occurrences of soil-water drought in the model. It allows SECHIBA to store more water in the soil during seasons of moisture convergence and to release it during seasons when precipitation is scarce. The soil memory is thus extended beyond seasonal scales. The global continental evaporation, in turn, is further increased. The sensitivity of the global water cycle to soil water capacity was quantified by Milly and Dunne (1994). The present model is less sensitive to water holding capacity changes than the one used by Milly and Dunne for their experiments. In their bucket model, evaporation control is dominated by soil moisture, while in more complex schemes, SECHIBA in the present case, the soil water content is one of many factors which modulate evaporation. This might explain why the sensitivity to water holding capacity is smaller in SECHIBA.

This study is devoted mainly to the interaction between the sub-grid scale variability in soil moisture with the vegetation. To each vegetation type, a soil water tile is attributed. Two extreme cases of spatial heterogeneity in soil moisture partitioning are tested. A more detailed analysis in one region of Amazonia where forest and savannah coexist is performed. Forest transpiration is limited in EXP2, where soil moisture is heterogeneous, by local soil
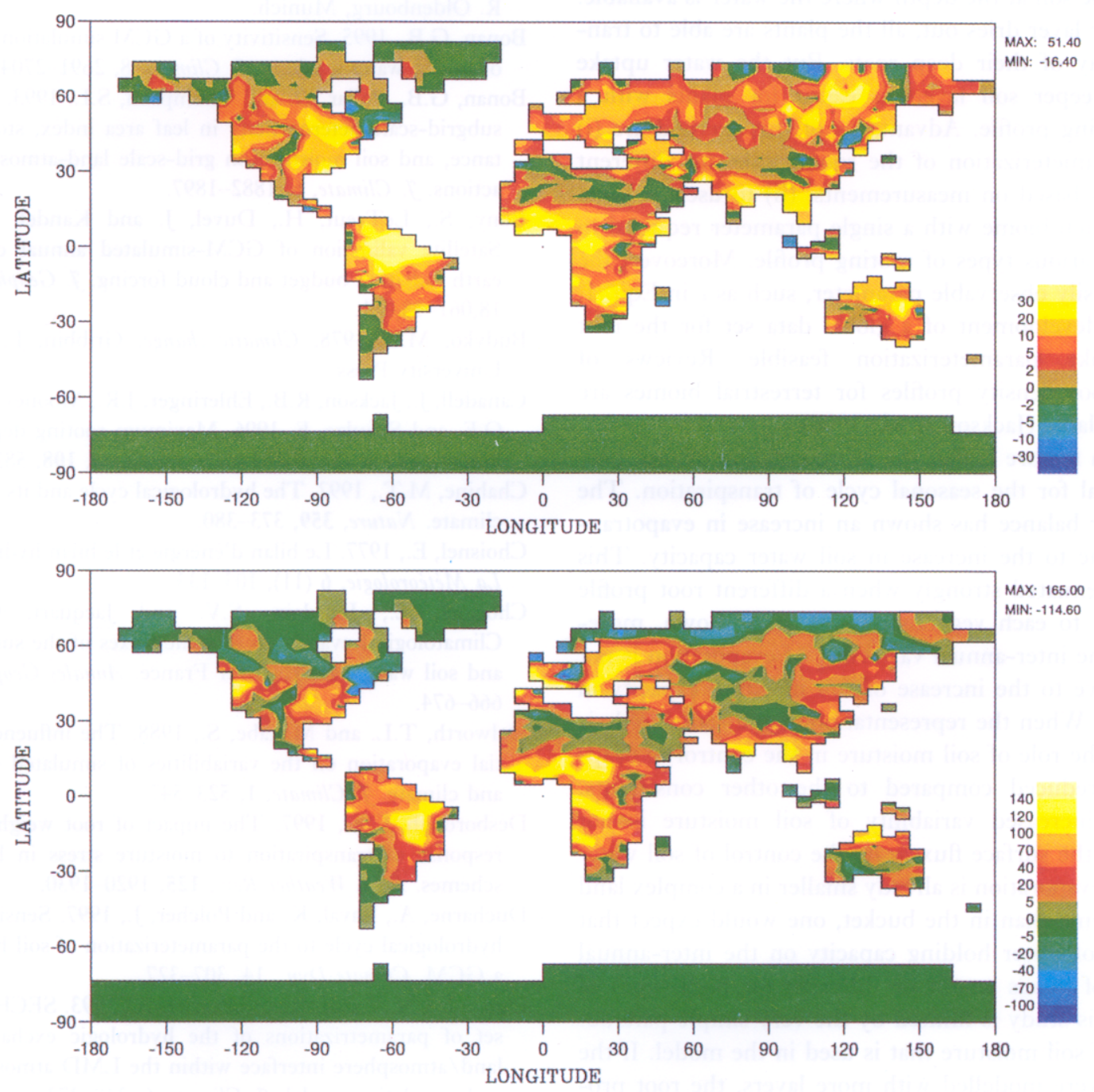

Fig. 11. Differences between the simulation conducted with a soil two metres deep on the REF. The first map displays the difference of the inter-annual variability of soil moisture content. It shows that the soil moisture inter-annual variability increases in most regions when soil mater holding capacity increases. The second map displays the difference in the amplitude of the mean annual cycle of soil moisture. It shows that the amplitude of the annual cycle of soil moisture increases with the soil water holding capacity. 
moisture content which is not sufficient to sustain large values of evapotranspiration during the dry season. In EXP1, which simulates a homogeneous soil moisture, forest can use water from the deep reservoir of the whole grid box. It is, thus, not limited by local soil water content. These experiments use a root profile density adjusted to each vegetation type. The parameterization to represent the root profile increases the control of evapotranspiration by the soil-plant system. Evapotranspiration is controlled mainly by net solar radiation when soil water is near saturation. As soon as soil begins to dry, transpiration of plants with shallower rooting profiles is managed by the root profiles which reduces it. In contrast, the transpiration of plants with a deeper rooting profile is not limited by the root water uptake.

The use of a root profile (instead of the root depth often used in Land Surface Schemes) allows modelling the uptake in the soil at the depth where the water is available. If the upper layer dries out, all the plants are able to transpire by way of their deep roots. But the water uptake from the deeper soil layers is easier for plants with a deeper rooting profile. Advantages of this method are (i) to be a parameterization of the root uptake for different biome types based on measurements, (ii) to use the same model for each biome with a single parameter required to depict the various types of rooting profile. Moreover, the use of an easily observable parameter, such as $c$ in Eqn. 1, makes the development of a global data set for the root water uptake parameterization feasible. Reviews of observed root density profiles for terrestrial biomes are already available (Jackson et al., 1996).

The main feature is that the representation of root profile is crucial for the seasonal cycle of transpiration. The global water balance has shown an increase in evapotranspiration due to the increase in soil water capacity. This effect is attenuated strongly when a different root profile corresponds to each vegetation type. It is shown, moreover, that the inter-annual variability of evaporation is not very sensitive to the increase of soil moisture capacity in the scheme. When the representation of the roof profile is improved, the role of soil moisture in the control of evaporation is reduced compared to the other constraints. Thus, the increased variability of soil moisture is not reflected in the surface fluxes. As the control of soil water content on evaporation is already smaller in a complex land surface scheme than in the bucket, one would expect that the impact of water holding capacity on the inter-annual variability of fluxes would be different for both types of scheme. This study is limited by the very simple parameterization of soil moisture that is used in the model. If the hydrology were modelled with more layers, the root profile would probably affect the surface fluxes in a more complex way.

\section{Acknowledgments}

We gratefully acknowledge the helpful comments of Katia Laval, Xavier Le Roux and Agnès Ducharne. We also thank Emmanuel Choisnel for providing us with measurements of water and energy fluxes over France, and Jennifer Crossley and Michael Bruen for their comments on the text. We thank the Institut du Développement et des Ressources en Informatique Scientifique for computer time allocated.

\section{References}

Akpo, L., 1992. Influence du couvert ligneux sur la structure et le fonctionement de la strate herbacée en milieu Sahélien. $\mathrm{PhD}$ thesis, ORSTOM, Collection séminaire et thèse, Paris, 174p.

Avissar, R. and Pielke, R.A., 1989. A parameterization of heterogeneous land surfaces for atmospheric numerical models. Mon. Weather Rev., 117, 2113-2136.

Baumgartner, A. and Reichel, E. 1975. The world water balance. R. Oldenbourg, Munich.

Bonan, G.B., 1995. Sensitivity of a GCM simulation to inclusion of inland water surfaces. 7. Climate, 8, 2691-2704.

Bonan, G.B., Pollar, D. and Thompson, S.L. 1993. Influence of subgrid-scale heterogeneity in leaf area index, stomatal resistance, and soil moisture on grid-scale land-atmosphere interactions. 7. Climate, 6, 1882-1897.

Bony, S., LeTreut, H., Duvel, J. and Kandel, R.S., 1992. Satellite validation of GCM-simulated annual cycle of the earth radiation budget and cloud forcing. 7. Geophys. Res., 97, 18,061-18,081.

Budyko, M.I., 1978. Climatic change. Gribbin, J., Cambridge University Press.

Canadell, J., Jackson, R.B., Ehleringer, J.R., Mooney, H.A., Sala, O.E. and Schulze, E. 1996. Maximum rooting depth of vegetation types at the global scale. Oecologia, 108, 583-595.

Chahine, M.T., 1992. The hydrological cycle and its influence on climate. Nature, 359, 373-380.

Choisnel, E., 1977. Le bilan d'énérgie et le bilan hydrique du sol. La Météorologie, 6 (11), 103-133.

Choisnel, E., Jourdain, S.V. and Jacquart, C.J., 1995. Climatological evaluation of some fluxes of the surface energy and soil water balances over France. Annales Geophysicae, 13, 666-674.

Delworth, T.L. and Manabe, S., 1988. The influence of potential evaporation on the variabilities of simulated soil wetness and climate. 7 . Climate, 1, 523-547.

Desborough, C.E., 1997. The impact of root weighting on the response of transpiration to moisture stress in land surface schemes. Mon. Weather Rev., 125, 1920-1930.

Ducharne, A., Laval, K. and Polcher, J., 1997. Sensitivity of the hydrological cycle to the parameterization of soil hydrology in a GCM. Climate Dyn., 14, 307-327.

Ducoudré, N., Laval, K. and Perrier, A., 1993. SECHIBA, a new set of parametrizations of the hydrologic exchanges at the land/atmosphere interface within the LMD atmospheric general circulation model. 7. Climate, 6, 248-273.

Dümenil, L. and Todini, E., 1992. A rainfall-runoff scheme for use in the Hamburg climate model. In: J. O'Kane (ed.) Advances in theoretical Hydrological Hydrology, A tribute to Fames Dooge, V. 1 of European Geophysical Society Series on Hydrological Sciences, pp. 129-157. Elsevier. 
Entekhabi, D. and Eagleson, P. 1989. Land surface hydrology parameterization for atmospheric general circulation models including subgrid scale spatial variability. 7. Climate, 2, 32-46.

Gale, M.R. and Grigal, D.F., 1987. Vertical root distribution of northern tree species in relation to successional status. Can. 7 . For. Res., 17, 829-834.

Gash, J., Nobre, C., Roberts, J. and Victoria, R. 1996. Amazonian Deforestation and Climate. Wiley, Chichester, UK.

Grouzis, M., 1988. Structure, productivité et dynamique des systèmes écologiques Sahéliens. PhD thesis, Mare d'Oursi, Burkina Faso. ORSTOM, Collection seminaire et thèse, Paris, $182 \mathrm{p}$.

Henning, D., 1989. Atlas of the Surface Heat Balance of the Continent. Gebruder Brontager-Berlin.

Hodnett, M., Oyama, M., Tomasella, J. and Marques Filho, A.d.O., 1996a. Comparisons of long-term soil water storage behaviour under pasture and forest in three areas of Amazonia. Amazonian Deforestation and Climate, pp. 57-77. Wiley, Chichester, UK.

Hodnett, M., Tomasella, J., Marques Filho, A.d.O. and Oyama, M., 1996b. Deep soil water uptake by forest and pasture in central Amazonia: prediction from long-term daily rainfall data using a simple water balance model. Amazonian Deforestation and Climate, pp. 79-99. Wiley, Chichester, UK.

Hulme, M., 1992. A 1951-80 global land precipitation climatology for the evaluation of general circulation models. Climate Dyn., 7, 57-72.

Jackson, R.B., Canadell, J., Ehleringer, R., Mooney, H.A., Sala, O.E. and Schulze, E. 1996. A global analysis of root distributions for terrestrial biomes. Oecologia, 108, 389-411.

Jarvis, P.G., 1976. The interpretation of the variations in leaf water potential and stomatal conductance found in canopies in the fields. Phil. Trans. Roy. Soc. London, Ser B, 273, 593-610.

Johnson, K.D., Entekhabi, D. and Eagleson, P., 1993. The implementation and validation of improved land-surface hydrology in an atmospheric general circulation model. $\mathcal{7}$. Climate, 6, 1009-1026.

Kalisz, P.J., Zimmerman, R.W. and Muller, R.N., 1987. Root density, abundance, and distribution in the mixed mesophytic forest of eastern Kentucky. Soil Sci. Soc. Am. F., 51, 220-225.

Korzun, V.I., Sokolov, A.A. and Budyko, M.I., 1974. World water balance and pater resources of the earth. Hydrometeorological Publishing House, Leningrad.

Koster, R.D. and Suarez, M.J., 1992. Modelling the land surface boundary in climate models as a composite of independent vegetation stands. 7. Geophys. Res., 97, 2697-2715.

Le Roux, X., 1995. Etude et modélisation des échanges d'eau et d'énérgie sol-végétation-atmosphère dans une savane humide (Lamto, Cote d'Ivoire). $\mathrm{PhD}$ thesis, Université Pierre et Marie Curie, Paris VI, 203pp.

Le Treut, H. and Li, Z.-X., 1991. Sensitivity of an atmospheric general circulation model to prescribed SST changes: Feedback effects associated with the simulation of cloud optical properties. Climate Dyn., 5, 175-187.

Manabe, S., 1969. Climate and the ocean circulation 1. the atmospheric circulation and the hydrology of the earth's surface. Mon. Weather Rev., 97, 739-774.

Milly, P.C.D. and Dunne, K.A., 1994. Sensitivity of the global water cycle to the water-holding capacity of land. 7 . Climate, 7, 506-526.
Mintz, Y., 1984. The sensitivity of numerically simulated climates to land-surface boundary conditions. In: J. Houghton (ed.), The Global Climate, pp. 79-105. Cambridge University Press.

Nepstad, D.C., Carvalho, C.R., Davidson, E.A., Jipp, P.H., Lefebre, P.A., Negrelros, G.H., da Silva, E.D., Stone, S.E., Trumbore, T.A. and Vieira, S., 1994. The role of deep roots in the hydrological and carbon cycles of Amazonian forests and pastures. Nature, 372, 666-669.

Perrier, A., 1975. Etude physique de l'évaporation dans les conditiones naturelles. Annales Agronomiques, 26, 105-123, 229-243.

Polcher, J., 1994. Etude de la sensibilité du climat tropical à la deforestation. PhD thesis, Université Pierre et Marie Curie, Paris VI, 185pp.

Polcher, J. and Laval, K., 1994. A statistical study of regional impact of deforestation on climate of the LMD-GCM.Climate Dyn., 10, 205-219.

Robock, A., Schlosser, C.A., Vinnikov, K.Y., Speranskaya, N.A. and Entin, J.K., 1997. Evaluation of AMIP soil moisture simulations. Global and Planetary Change (in press).

Rowntree, P.R., 1995. The mater budget of middle latitude continental regions. A modelling and observational study. Technical report, Hadley Centre Climate Research Technical Note CRNT 59, Hadley Centre, Meteorological Office, Bracknell, U.K.

Rowntree, P.R. and Lean, J., 1994. Validation of hydrological schemes for climate models against catchment data. 7. Hydrol., 155, 301-323.

Sadourny, R. and Laval, K., 1984. January and July performance of the LMD general circulation model. New perspectives in climate modelling, pp. 173-197. Elsevier, Amsterdam.

Shukla, J. and Mintz, Y., 1982. Influence of land-surface evaporation on the earth's climate. Science, 215, 1498-1501.

Shuttleworth, J.W., 1988a. Evaporation from Amazonian rainforest. Proc. $R$ Soc. Lond., 233, 321-346.

Shuttleworth, W.J., 1988b. Macrohydrology-the new challenge for process hydrology. F. Hydrol., 100, 31-56.

Viterbo, P., 1994. A review of parameterization schemes for land surface processes. Proceedings of the Seminar on Parameterization of subgrid scale physical processes, ECMWF, ed., pp. 219-275. ECMWF, Reading, UK.

Warrilow, D., Sangster, A. and Slingo, A., 1986. Modelling of land surface processes and their influence on European climate. Technical Report 38, Meteorological Office.

Wild, M., Ohmura, A., Gilden, H. and Roeckner, E., 1995. Regional climate simulation with a high resolution GCM: surface radiative fluxes. Climate Dyn., 11, 469-486.

Wood, E., Lettenmaier, D. and Zartarian, V., 1992. A land-surface hydrology parameterization with subgrid variability for general circulation models. 7. Geophys. Res., 97,2717-2728.

Wright, 1., Gash, J. and da Rocha, H., 1996. Modelling surface conductance for Amazonia pasture and forest. Amazonian Deforestation and Climate, pp. 437-458. Wiley, Chichester, UK.

Wright, I.R., Gash, J.H.C., Da Rochas, H.R., Shuttleworth, W.J., Nobre, C.A., Maitelli, G.T., Zamparoni, C.A.G.P. and Carvalho, P.R.A., 1992. Dry season micrometeorology of central Amazonian ranchland. Quart. 7. Roy. Meteorol. Soc., 118, 1083-1099. 